\title{
Psicologia Filosófica no Século XIX: Faculdades da Alma e Relações entre Inteligência, Sensibilidade e Vontade
}

\author{
Philosophical Psychology in the 19 ${ }^{\text {th }}$ Century: Soul Faculties \\ and Relations among Intelligence, Sensibility and Will
}

\author{
Raquel Martins de Assis* \\ Universidade Federal de Minas Gerais
}

\begin{abstract}
Resumo
Situado no campo da História dos saberes psicológicos no Brasil, o presente artigo apresenta dois compêndios produzidos em Minas Gerais nos anos de 1847 e 1849, cujo tema é a descrição da estrutura e do funcionamento das faculdades da alma humana e da origem das idéias. As obras trazem uma sistematização sobre os conceitos de alma, inteligência, consciência, sensibilidade e vontade. A partir da descrição de tais conceitos é possível evidenciar a filiação destas obras às matrizes teóricas, principalmente francesas, tais como a ideologia e o espiritualismo eclético. Ao final comenta-se a relação entre autores, e o modo de apropriação de conhecimento textual, como evidenciado na escrita dos autores mineiros pela forma de se referenciar aos originais europeus. Palavras-chave: História da psicologia; Século XIX; Psicologia filosófica.
\end{abstract}

\begin{abstract}
Set in the field of the history of psychological knowledge, the present article presents two publications issued in the state of Minas Gerais in 1847 and 1849, approaching the description of the structure and performance of the faculties of the human soul and the genesis of the ideas. The works unveiled systematization over the concepts of the soul, intelligence, consciousness, sensibility and will. From the description of such concepts it is possible to bring into evidence the theoretical matrixes, mainly French ones, such as the ideology and the eclectic spiritualism. At the end, it is noted the relationship between the authors and the procedures to get property of the textual knowledge, as it is evidenced in the texts by the writers from Minas Gerais, based on the way Europeans original works are referred to.

Keywords: History of psychology; $19^{\text {th }}$ century; Philosophical psychology.
\end{abstract}

De acordo com estudos em História da Psicologia, a emergência do saber psicológico no Brasil no período colonial e imperial esteve fortemente relacionada às produções de campos de conhecimento como a Educação, a Filosofia e a Medicina (Alberti, 2003; Antunes, 1998; Campos, 1992; Jacó-Vilela, Esch, Coelho, \& Rezende, 2004; Massimi, 1989; Nepomuceno \& Campos, 2004).

No século XIX, a província de Minas Gerais foi cenário da publicação de duas interessantes obras sobre psicologia filosófica, destinadas a discutir a estrutura e a hierarquia entre as faculdades da alma e a origem das idéias do espírito humano. Em 1847 João Antônio dos Santos publica a obra $O$ esqueleto das faculdades e a origem das idéias do espírito humano, obra mui útil para os moços que se applicão ao estudo de Philosophia, impressa pela Tipografia Episcopal de Mariana- MG. Pouco tempo depois, em 1849, Rodrigo José de Ferreira Bretas escreve o Novo esqueleto das faculdades e origem das idéias do espírito humano segundo os princípios de Mr. Larominguiere ou da psicologia vigente, impresso pela Tipografia do Bom

* Endereço para correspondência: Universidade Federal de Minas Gerais, Faculdade de Educação, Av. Antônio Carlos, Pampulha, Belo Horizonte, MG, Brasil, CEP31270-901. Tel.: (31) 3499 5326. E-mail: raamart@yahoo.com.br
Senso em Ouro Preto - MG e publicado pela primeira vez em 1854.

O objetivo do presente artigo é trazer uma apreciação histórica sobre as duas obras dos religiosos mineiros, comparando a síntese das idéias desenvolvidas pelos autores com os autores europeus que serviram de consulta. Deste modo, pode-se ter uma maior compreensão da definição da psicologia filosófica ensinada em instituições educacionais nesse período, bem como mostrar a contribuição dos compêndios utilizados para o ensino de Filosofia e Teologia Moral para a constituição de saberes psicológicos.

$\mathrm{O}$ artigo está organizado do seguinte modo: primeiro ofereço o contexto no qual os autores mineiros escreveram os breves manuais sobre as faculdades da alma. A seguir descrevo os conceitos de inteligência, de sensibilidade e de vontade contidos em cada obra. E, finalmente, comparo a síntese das idéias desenvolvidas pelos autores mineiros com os manuais e autores europeus que lhes servem de referência.

\section{Os Autores Mineiros e suas Obras sobre as Faculdades da Alma}

No século XIX, a psicologia era ensinada nos Seminários e Colégios, dedicados à educação da mocidade, como parte da Filosofia ou da Teologia Moral (Alberti, 2003; 
Antunes, 1998; Massimi, 1989). O ensino da psicologia era marcado pela presença de diversas doutrinas filosóficas utilizadas para descrever a estrutura e funcionamento da alma humana em seus variados aspectos, tais como o espírito, o eu, a consciência, a sensibilidade, o pensamento, as emoções, as relações entre corpo e alma, entre outros (Alberti, 2003; Antunes 1998; Massimi, 1989).

Anteriormente, no período colonial, o conceito de alma difundido em obras e compêndios fundamentava-se, sobretudo, na Escolástica, principalmente nas teorias aristotélicotomistas divulgadas pela Companhia de Jesus (Massimi, 1990). Com a expulsão dos jesuítas do Brasil, foi preciso encontrar novas teorias para o ensino de filosofia, capazes de substituir a Escolástica portuguesa. Então, no país de maneira geral e também em Minas Gerais, os saberes sobre a alma humana encontraram suas explicações principalmente nas obras de Luiz Antônio Verney (1713-1792) e nas Instituições de Lógica (escrito em 1759 e publicado em 1786/1977) de Antônio Genovesi (1713-1769) (Campos, 1992; Paim, 1977; Rodrigues, 1986).

Além do empirismo mitigado de Verney e Genovesi, da obra do jesuíta Sigismund von Storchenau (1731-1798) e do idealismo alemão (Antunes, 1998; Massimi, 1989; Paim, 1977; Rodrigues, 1986), os intelectuais do século XIX começaram a fundamentar seus saberes sobre a alma humana também no espiritualismo eclético, advindo dos ideais franceses. Sendo assim, no século XIX a psicologia foi largamente ensinada em diversos programas e compêndios, cujos temas podiam ser elaborados por diferentes correntes de pensamento presentes no ensino de filosofia ao longo do período em que o país foi colônia e império. São exemplos dessas obras encontradas no século XIX e produzidas no interior de Colégios e Seminários as Teses filosóficas sobre a psicologia do homem as quais se propõe defender em público no Imperial Seminário de São Joaquim (1830), escritas por Queiroz, Pereira e Couto (Alberti, 2003), Ensaio de Philosophia Moral ou de Ethica o qual se propoem defender em publico no Imperial Seminario de S. Joaquim Marcos Cardoso de Paiva e Tristao Soares de Paiva debaixo da direcao de Fr. José de Polycarpo de Santa Gertrudes (1826) e Compendio de Philosophia Racional (1852), obra de cunho tomista redigida por D. Afonso de Moraes Torres (Massimi, 1990). Massimi (1990), em suas pesquisas sobre a psicologia ensinada em instituições educacionais do século XIX, ainda levanta uma série de obras ligadas a diferentes correntes de pensamento, como as de José Soriano de Souza que, em livros datados de 1867 e 1871, trata da alma humana partindo de um enfoque tomista e Silvestre Pinheiro Ferreira, empirista sensualista que descreve os fatos psíquicos a partir da sensação e do sentir.

Nepomuceno e Campos (2004), ao realizarem o levantamento e catalogação de fontes para a história dos saberes psicológicos em Minas Gerais, apontam as obras Esqueleto das faculdades e origem das idéias e Novo Esqueleto das faculdades da alma e origem das idéias do espírito humano como duas fontes representativas dos debates filo- sóficos ocorridos em Minas Gerais no século XIX e especialmente importantes para a história da psicologia.

A obra Esqueleto das faculdades e origem das idéias, obra mui útil para os moços que se applicão ao estudo de Philosophia de João Antônio dos Santos é um pequeno livro de 16 páginas e para este estudo foi utilizada a edição de 1847. O Novo esqueleto das faculdades da alma e origem das idéias do espírito humano segundo os princípios de Mr. Laromiguère de Rodrigo José de Ferreira Bretas contém 45 páginas e aqui foi utilizada a edição de 1854.

João Antônio dos Santos era natural de Diamantina, filho de tradicional família que se destacou no cenário político e econômico da cidade. Realizou seus estudos de filosofia e teologia nos Colégios do Caraça e de Congonhas do Campo, completando sua formação em Roma. Mais tarde tornou-se vice-reitor do Seminário de Mariana e professor das Cadeiras de Filosofia e Dogmas. Durante esta época, em Mariana, Santos esteve ligado às produções da Tipografia Episcopal de Mariana, tornando-se o principal responsável pela edição do jornal religioso Selecta Catholica. Em 1864 tornou-se bispo de Diamantina, fundando na cidade o Seminário Episcopal de Diamantina, o Colégio Nossa Senhora das Dores para instrução feminina e o Asilo de Órfãs.

Rodrigo José de Ferreira Bretas, por sua vez, era natural de Cachoeira do Campo. Assim como João Antônio dos Santos, Ferreira Bretas fez seus estudos no Colégio do Caraça e depois em Congonhas do Campo. Ocupou a cadeira de Filosofia e Retórica em Barbacena e depois no Colégio da Assunção em Ouro Preto. Mais tarde, em 1858, foi nomeado Diretor Geral da Instrução em Minas Gerais, época em que buscou modernizar a estrutura do ensino em Minas Gerais, tendo como um de seus aspectos o cuidado com a escolha dos livros didáticos a serem utilizados nas escolas.

Pelos percursos dos dois autores no campo da educação, vemos que João Antônio dos Santos e Rodrigo José de Ferreira Bretas estiveram envolvidos em iniciativas bastante importantes no século XIX no Brasil. Eles participaram da fundação de Colégios, do ensino de filosofia e da impressão, circulação e escolha de livros voltados para a educação escolar. Entre as obras publicadas destacam-se obras de Teologia e Filosofia e o jornal religioso Selecta Catholica (1846-1847) organizado por Santos em colaboração com D. Antônio Viçoso. Ferreira Bretas, por sua vez, mais ligado aos ideólogos e ao espiritualismo francês, realizou um plano de estudo para os estabelecimentos de ensino mantidos pelo governo da província (Leite, 2005; Rodrigues, 1986).

Acompanhando o movimento nacional de produção e utilização de compêndios para o ensino de psicologia, alguns exemplares do Esqueleto das faculdades e a origem das idéias do espírito humano de João Antônio dos Santos foram adquiridos pelo Seminário de Mariana, o que evidencia a sua utilização pelos seminaristas. De fato, na introdução ao seu livro Santos afirmou tê-lo escrito, a fim de que os jovens estudantes de filosofia tivessem uma 
alternativa mais viável economicamente do que a aquisição dos compêndios de Genovesi, Storchenau ou Ponelle.

Existem muitas relações entre o Esqueleto das faculdades da alma e origem das idéias do espírito humano de João Antônio dos Santos e o Novo Esqueleto das faculdades da alma de Ferreira Bretas além do título, que por si só já estabelece um diálogo muito claro entre os dois livros, pois ambos seguem basicamente a mesma estrutura, iniciando-se pelo conceito do que é alma, seguido da discussão sobre a inteligência e pensamento, depois a sensibilidade, a origem das idéias e as relações entre corpo e alma.

A estrutura das obras adotada pelos autores evidencia temas comuns na época e segue basicamente os mesmos parâmetros de programas de cursos de filosofia em Faculdades, Seminários e Escolas de seu tempo. Massimi (1989) descreve alguns desses programas nos quais normalmente encontramos tópicos como enumeração e apreciação das faculdades da alma, discussões sobre o Eu e sobre a unidade da alma, liberdade, passividade e atividade da alma, relações entre corpo e alma, entre outros assuntos.

\section{A Descrição da Inteligência, da Sensibilidade e da Vontade no Esqueleto das Faculdades de João Antônio dos Santos}

João Antônio dos Santos, seguindo idéia corrente na época, utiliza o termo parte psicológica para designar o ramo da Filosofia responsável pela descrição, pela discussão das faculdades da alma humana e pelo processo por meio do qual se dá a aquisição do conhecimento e das idéias. No Esqueleto das faculdades a alma é definida como um ente dotado de força, capaz de agir impulsionado pela sua relação com os objetos. Embora a força, ou capacidade de ação, seja inerente à totalidade da alma, existem momentos em que a alma fica passiva. De acordo com idéia vigente na época, tanto Santos como Ferreira Bretas admitem a atividade como característica central da alma, entendendo-a como uma força que leva ao movimento. Da maneira como a atividade da alma se organiza, surgem as faculdades ou modos de obrar que se expressam de três modos: a inteligência percebe ou conhece os objetos, a sensibilidade experimenta prazer ou pena diante da presença dos objetos e a vontade abraça ou rejeita-os.

Como um verdadeiro esqueleto, cada uma dessas faculdades pode se subdividir em várias outras. Desse modo, a inteligência é formada pela consciência, pela percepção externa ou sentidos e pelo entendimento. A sensibilidade é dividida em física, moral e intelectual e é definida como experiência de prazer ou pena diante dos objetos. A vontade, por sua vez, é responsável pela volição, ou seja, o ato a partir do qual o espírito abraça ou rejeita algo e pode ser caracterizada pela vontade necessária e pela liberdade.

No esquema traçado pelo autor, a inteligência tem a primazia na hierarquia das faculdades:

A intelligencia tem o primeiro lugar na genealogia das faculdades. Por quanto ainda que a impressão dos objectos na alma seja primeira que qualquer advertencia do espirito, com tudo, como diz o antigo proloquio
Ignotti nulla cupido, não ha sentimento, não há prazer ou pena sem o conhecimento do objecto que o produz; e por consequencia não há tambem vontade. E por que os sentimentos são os motivos que alliciao a vontade, segue-se que este deve occupar o primeiro lugar depois da sensibilidade ou o terceiro na ordem genealogica. (Santos, 1847, p. 2).

Na dinâmica do conhecimento apresentada no Esqueleto das faculdades, em primeiro lugar a alma é afetada pela sensação provocada por um objeto e em seguida a inteligência age sobre esta sensação, a fim de conhecer o objeto. Embora o autor reconheça que as faculdades alteram-se mutuamente, provocando reações uma sobre a outra, não existe a possibilidade de haver sentimento, prazer, pena, desejo ou qualquer conhecimento sobre a sensação, sem que haja primeiro um movimento da inteligência. Por ser a primeira na genealogia, a inteligência desperta a sensibilidade e exerce um certo controle sobre esta, pois é capaz de modificá-la, mesmo diante das causas externas. Assim, a maneira como percebemos os fenômenos sensíveis pode ser afetada ou modificada pela consciência, pelas idéias e pela imaginação.

Dependendo do tipo de atividade que exerce e do objeto para o qual está voltada, a inteligência se manifesta como consciência, sentidos ou entendimento:

A Intelligencia pois, em quanto nos dá o conhecimento do eu e suas affeições ou do mundo interno, chama-se consciência:em quanto porem nos pôe em relação com os objectos que não são o eu e suas affeições, isto he, com o mundo externo, chama-se percepção externa, que dirigindo-se ao mundo physico, toma o nome de faculdade dos sentidos ou simplesmente os sentidos e levando-nos ao conhecimento do mundo metaphysico, chamaremos intelligencia superior ou entendimento. (Santos, 1847, p. 2).

Desse modo, são três os objetos para os quais esta faculdade se volta quando conhece: o mundo interno ou eu, o mundo físico e o mundo metafísico. Mas para conhecer estas realidades, a consciência, os sentidos e o entendimento necessitam das auxiliares: atenção, abstração, generalização, razão, memória, associação de idéias e imaginação.

A atenção é uma das faculdades mais importantes para a cognição, pois de acordo com Santos "por ella he que nós nos inteiramos do estado da nossa alma e do mundo externo. Se a alma não dirige a sua energia aos objectos que a tocão, estes apenas lhes deixão leves vestígios" (Santos, 1847 , p. 2). De fato, também nos escritos de outros autores da época como os próprios ideólogos, atribui-se a tal faculdade um papel primordial na cognição, pois é por meio dela que se dá a primeira relação da inteligência humana com os objetos. A atenção, inseparável da abstração e intimamente ligada à sensibilidade, é a faculdade responsável por direcionar a alma para o conhecimento. Por sua vez a abstração auxilia-a, fornecendo o segundo passo do conhecimento que é separar os objetos que estão unidos: "por quanto o espírito sendo limitado, não pode abranger muitos objectos; necessita concentrar-se em huns retirando-se de outros" (Santos, 1847, p. 4). Assim, os primeiros passos 
Assis, R. M. (2009). Psicologia Filosófica no Século XIX: Faculdades da Alma e Relações entre Inteligência, Sensibilidade e Vontade.

da cognição são dados pela atenção que direciona a energia da alma para uma determinada realidade e pela abstração que visa o objeto, a fim de que ele se destaque do cenário em que está inserido e possa ser conhecido.

A generalização é a faculdade por meio da qual a alma estende uma idéia a uma classe inteira e é responsável pela capacidade de classificar, ordenar e remeter-se a idéias simples que, colocadas em relação pela razão, formam noções gerais e juízos. A razão, por sua vez, é concebida como raciocínio ou capacidade de formular juízos diante dos nexos e relações entre os objetos do conhecimento já estabelecido pela atenção, pela abstração e pela generalização. Daí que a razão seja entendida como dependente das faculdades anteriores. Os papéis da generalização e da razão são importantes para que o ser humano seja capaz de compreender as relações entre unidade e conjunto ou elementos e sistemas que, conseqüentemente, propiciam a criação de esquemas mais elaborados de pensamento e de ação sobre a realidade. Inseridas nessa capacidade de complexidade própria da inteligência humana, estão também a associação de idéias e a imaginação, responsáveis pela criação de sistemas tais como as noções de belo e grotesco, próprias da arte, e pelo conhecimento de verdades sublimes. A memória parece contribuir também para a percepção do sublime relacionado ao Belo, ao Bom e à Verdade, pois é responsável pela conservação e reconhecimento dos conhecimentos adquiridos, mas também das idéias metafísicas, morais e gerais.

A sensibilidade, segunda da hierarquia no Esqueleto, é antecedida pela inteligência e precedida pela vontade e é definida pelo autor como faculdade de "gozar os prazeres ou penas tanto do corpo como do espirito e coração" (Santos, 1847, p. 6). Esta faculdade é denominada sensibilidade física quando os órgãos do corpo têm impressões agradáveis ou desagradáveis diante dos objetos sensíveis e é chamada de sensibilidade moral e intelectual, quando sente prazeres ou penas ao se deparar com as percepções do Belo, do Justo e de seus contrários. Estas impressões de pena ou prazer são os afetos e paixões da alma.

Definida como uma faculdade originada das duas anteriores, a vontade é responsável pela adesão livre aos objetos e pela capacidade de fruir ou resistir às paixões provocadas pela sensibilidade. Assim, a vontade é a terceira na genealogia do Esqueleto porque é nela que se dá a finalização do percurso do conhecimento: impressão do objeto na alma, ação da inteligência e movimento do desejo sobre ele e finalmente a adesão ou recusa do objeto. A vontade é bastante complexa por inscrever uma série de relações iniciadas nas faculdades anteriores que se finalizam na conduta. Desse modo, o percurso completo do conhecimento envolve não somente as capacidades intelectuais, mas a sensação, os afetos, as paixões e a ação, ou seja, a totalidade das faculdades da alma humana em suas relações com o corpo.

Esta dinâmica das faculdades da alma, embora didaticamente separada por Santos a fim de explicá-la, é percebida pela consciência como um ato único imediato e pessoal:
He facto incontestavel, que os nossos actos nos parecem productos de nossa vontade; que quando nos resolvemos depois da deliberação, sabemos que esta determinação nos pertence, que a poderíamos tomar e deixar de tomar, e que a nós imputamos a sem razão, se ella he opposta aos principios da moral, e o merito della quando he conforme com esses princípios. Prova esta imputação a convicção em que estamos de que a determinação com $o$ acto que se lhe seguio nos pertence como propriedade. Neste ponto falla a consciencia claramente, e seo testimunho he irrecusável. (Santos, 1847, p. 10).

Assim, a percepção do eu como unidade e posse de si mesmo e de seus atos é permitida pela maneira como as faculdades da alma se organizam e funcionam. Isto é possível porque a consciência, uma das facetas da inteligência, é capaz de perscrutar a alma e tomar conhecimento do que nela acontece. A consciência é também responsável pelo sentimento e pela certeza da liberdade como experiência genuinamente humana, já que observa e testemunha o trajeto feito pelo espírito desde a impressão advinda da sensação até a tomada de decisão da pessoa diante das inúmeras possibilidades e escolhas.

A liberdade é entendida como uma perfeição da vontade, segundo a qual o ser humano não pode ser determinado pelas circunstâncias externas ou internas que se lhe apresentam, pois o homem percebe seus atos como pertencendo a ele e assim sente-se livre e julga-se livre. Se não fosse assim, de acordo com Santos, as pessoas poderiam atribuir a responsabilidade de suas condutas a causas superiores e exteriores a elas como se fossem meros joguetes do destino. Desse modo, para o autor, a liberdade é uma evidência para a consciência.

\section{O Pensamento e a Sensibilidade no Sistema de Psicologia do Novo Esqueleto das Faculdades de Rodrigo José de Ferreira Bretas}

Ferreira Bretas, assim como Santos, define a alma como um ente dotado de atividade e força. Porém, fundamentando-se no sistema de divisão das faculdades da alma, realizado nas Leçons de philosophie ou Essai sur les facultés de l'âme (1823), de Pierre Laromiguière (1756-1837) e na obra Logique classique dáprès lês príncipes de philosophie de M. Laromiguière (1834), de Jean-Ferreol Perrard (1795?), o autor divide a alma em capacidade de sentir e faculdade de obrar, cujas características são, respectivamente, a passividade e a atividade. Assim, as faculdades são ativas e modificam a si mesmas, já a sensibilidade, por ser passiva, sofre a ação externa e é modificada pelos fenômenos do mundo interno e externo.

Desse modo, a atividade é propriedade de apenas uma parte da alma, diferenciando-se do Esqueleto das faculdades ao descrever o espírito ativo em sua totalidade, ou seja, quando pensa, sente e quer. Em compêndios dedicados à psicologia filosófica, a atividade pode ser entendida de diversas formas, mas nas duas obras mineiras ela aparece como princípio originário das faculdades, já que estas 
são sempre entendidas como as propriedades da alma humana, capazes de realizar as modificações psíquicas e de moverem a si mesmas.

No Novo Esqueleto as faculdades da alma humana podem ser de dois tipos: intelectuais ou entendimento e morais ou vontade. O conjunto dessas faculdades denomina-se pensamento. Desse modo, a alma humana é dividida em sensibilidade e pensamento. A atividade do pensamento consiste em separar os elementos recebidos de forma caótica pela sensibilidade, a fim de ordená-los em um sistema.

Tudo quanto o homem possa conhecer amontoa-se em sua passibilidade, durante o volver dos seus dias, mas nem tudo por isso está feito para elle: por quanto é mister que a luz da actividade, penetrando n' esse cahos, separe esses elementos inertes, os relacione entre si, redija-os n' um systema, á fim de se poder considerar formada nossa intelligencia e enrequecida de verdadeiros conhecimentos. (Ferreira Bretas, 1854, p. 1).

O sistema ou conjunto de conhecimentos que formam a inteligência é adquirido por meio de três faculdades intelectuais: atenção, comparação e raciocínio. A atenção é responsável pela observação do fenômeno isolado, enquanto que a comparação e o raciocínio estabelecem relações entre um determinado fenômeno e outras circunstâncias. Nesse sentido, a inteligência tem sua origem na capacidade da alma de alcançar uma complexidade ao estabelecer relações que partem da atenção a um objeto isolado:

quem não dirá com Mr. Laromiguière que a alma, na obtenção dos fins acima indicados, exerce três poderes distinctos ou faculdades? que attendeu simplesmente para as cousas, comparou-as entre si depois, e ultimamente sobre ellas raciocinou, fazendo déste ultimo modo nascerem novas relações das primeiramente conhecidas pela comparação? (Ferreira Bretas, 1854, p. 6).

A atenção, a comparação e o raciocínio podem se tornar mais complexos e se diversificar em seus modos de ação a ponto de dar origem a faculdades tais como a imaginação, a reflexão, a abstração, a memória, o espírito e finalmente o gênio. Particularmente a memória tem um papel muito interessante no conjunto de ações exercidas pela alma, a fim de organizar a inteligência, pois funciona como um depósito de idéias e de todos os produtos da atividade e é a responsável pela evocação das idéias esquecidas e pelo reconhecimento de nossa identidade como um eu. Sem a memória ficaríamos reduzidos ao nada, pois, de acordo com Sócrates, "o homem tanto sabe quanto se lembra" (Ferreira Bretas, 1854, p. 11).

Embora, a alma possa ser dividida em duas propriedades diferentes, Ferreira Bretas afirma, assim como João Antônio dos Santos, a identidade e a unidade do eu, dada a partir da consciência:

O mesmo á respeito de nossa unidade: quem poderia, ser o mesmo sem ser um? ... - Eis aqui um argumento que se poderá dizer vicioso; mas o que oppor á decisão da consciencia? e como decide ella? Em mim ella decide que sou o mesmo, um e indivisivel. E não será ella a mesma em todas? A consciencia refunde-se na natureza do homem. A identidade pois do eu e sua unidade é um phenomeno da consciencia, cuja veracidade a memoria ajuda á estabelecer. (Ferreira Bretas, 1854, p. 36).

A ação da memória, por sua vez, é originada pelo cérebro, aparecendo aí a relação entre a consciência, a formação das idéias e os aspectos fisiológicos do corpo humano.

Além da descrição dos aspectos intelectuais, o autor mineiro trata também das faculdades morais: o desejo, a preferência e a liberdade. Essas três faculdades são fundamentais para a dinâmica da alma humana, já que o homem se destina verdadeiramente à felicidade e não apenas ao conhecimento das coisas. A felicidade é o complemento necessário do entendimento, pois para o autor do Novo Esqueleto, o homem não deseja apenas ser sábio, mas ser feliz.

O conceito de felicidade coincide com bem-estar e é definido como a tendência própria e inerente à natureza do ser humano para o sentimento-prazer e repulsa ao sentimento-dor. A busca do bem-estar, presente em qualquer ação humana, cabe à vontade realizar. Assim, a dinâmica do desejo nasce quando a alma, ao experimentar uma falta ou dor, cria uma necessidade e, então, busca um objeto para satisfazê-la ou tranqüilizá-la, a fim de parar o mecanismo do mal-estar inicial.

Depois que, por meio do desejo, a alma identifica os objetos em conexão com o seu bem-estar, então se dá a preferência, ou seja, a escolha de um entre todos os objetos apresentados. Realizada a preferência, há ainda um último movimento da alma que completa o movimento da vontade: o querer, ou seja, a adesão ao objeto preferido, o que acontece por meio da liberdade. Assim, de acordo com Ferreira Bretas e com os princípios de Perrard e Laromiguière, existe uma hierarquia, segundo a qual a alma, para exercer a liberdade, prescinde do desejo e da preferência. Para raciocinar, precisa primeiro da atenção e da comparação. Para que os atos da inteligência e da vontade se completem e as idéias possam se organizar em um sistema, é necessário, em primeiro lugar, afetar a sensibilidade, pois não existe nada no pensamento que não tenha passado pelos fenômenos da sensibilidade.

Assim como o pensamento é dividido em seis faculdades elementares, a sensibilidade é formada por quatro espécies de sentimento: sensação, sentimento da ação das faculdades, sentimento-relação e sentimento moral ou inato.

No Novo Esqueleto, as sensações, por meio das quais o ser humano percebe o mundo sensível pelos órgãos do sentido, se referem apenas a um tipo de sentimentos possíveis à alma, pois os outros acontecem quando o pensamento inicia sua ação sobre a sensação. Assim, primeiro acontece a sensação, mas logo em seguida, a alma percebe a ação das faculdades da alma sobre a sensibilidade. Há, portanto, um sentimento que acompanha a atenção. De maneira ainda mais diferenciada, a alma sente quando o pensamento exerce a comparação sobre a sensibilidade e estabelece relações entre idéias. E por último, existem os sentimentos inatos e naturais que têm lugar quando o ser humano se depara com a justiça e a injustiça. 
Assis, R. M. (2009). Psicologia Filosófica no Século XIX: Faculdades da Alma e Relações entre Inteligência, Sensibilidade e Vontade.

Ferreira Bretas dedica algumas páginas de sua obra à discussão do sentimento moral inato e natural ao ser humano. Para isso, o autor define os fundamentos da moral como gravados no coração do gênero humano, já que são inerentes ao homem e independentes do aprendizado. De fato, mesmo "longe dos livros, dos mestres e das opiniões" (Ferreira Bretas, 1854, p. 19) a moral está sempre presente de uma maneira particular, fazendo com que se queira o bem aos outros e a si. Como são gravados, impostos passivamente na alma pelo Criador e, conseqüentemente, são universais e inatos, os sentimentos morais podem ser definidos como sensibilidade e não como faculdade. Entretanto, a idéia moral não é inata, pois é fruto de uma ação da alma sobre a invariabilidade moral. As faculdades se voltam sobre os sentimentos morais, estudam-nos e, finalmente, transformam-nos em idéia.

Neste momento de sua obra, Ferreira Bretas preocupa-se em manter afastado de si a pecha de materialista, defendendo-se de tal acusação ao afirmar a existência do sentimento moral inato ao homem e deixando clara sua discordância de Laromiguiére apenas nesse ponto.

Partindo dessa perspectiva, para Ferreira Bretas o conceito cartesiano de idéias inatas é inadmissível, pois, sendo provenientes da ação das faculdades sobre o sentimento, as idéias pressupõem atividade e, portanto, são incompatíveis com qualquer operação de imposição. O conceito de inato, por sua vez, implica em inscrição ou imposição de algo na alma por um agente externo, o que, do ponto de vista de Perrard e Laromiguière, seria uma contradição com a natureza ativa do pensamento.

No Novo esqueleto, as idéias são descritas como produção das faculdades em que se há de fazer a distinção entre causa e origem. O sentimento é a origem das idéias e as faculdades, a causa delas existirem e se ordenarem. Aliás, para Ferreira Bretas, assim como para Perrard, o sistema de explicação de Laromiguière sobre a alma seria superior ao de Condillac e ao de muitos outros sistemas filosóficos, exatamente por estabelecer uma distinção entre princípios e causas no que diz respeito às faculdades humanas:

Le principe, la source ou l'origine, c' est, comme on vient de le dire, l'idée par laquelle tout commence et de laquelle tout dérive. Le principe fait partie d'une chaine dont il est le premier anneau; la cause, au contraire, se trouve en dehors. ... Selon la judicieuse observation de M.Laromiguière, si la philosophie s'est précipitée dans un abîme d'extravagances, c'est pour avoir confondu le principe avec la cause, ou la cause avec le principe. (Perrard, 1834, p. 19).

Ao utilizar no Novo esqueleto o argumento de Perrard e afirmar que as idéias se originam do sentimento, o autor classifica como erro a atribuição da origem das idéias às faculdades. Refuta, então, a afirmação de João Antônio dos Santos, segundo a qual a origem e o princípio das idéias está na relação que as faculdades da alma estabelecem com os diversos objetos. Para Ferreira Bretas as idéias são entendidas como efeitos do entendimento, definidos como produtos das faculdades, ou seja, causadas por uma ação das faculdades sobre os sentimentos que afetam a alma.
Dessa produção deriva a inteligência entendida como somatório das idéias.

\section{Matrizes Teóricas das Obras e suas Relações com a Psicologia Filosófica da Época}

Um dos aspectos comuns às duas obras aqui apresentadas é uma certa crítica às teorias e aos compêndios sobre Psicologia até então utilizados nos Colégios e Seminários. Mas ao mesmo tempo, os autores mineiros utilizam e dialogam com essas teorias na apresentação de seus textos. Assim, Santos chama de rançoso a Antônio Genovesi, pensador italiano, cujas Instituições de lógica eram o manual oficial para o ensino de Filosofia em Minas Gerais (Paim, 1977; Rodrigues, 1986).

Rodrigues (1986) afirma que o Esqueleto das faculdades tentava ser uma superação do empirismo mitigado, representado pelo sistema de Genovesi. De fato, a maneira de Santos apresentar e de conceituar a alma humana é muito diferente daquela realizada por Genovesi nas Instituições de Lógica.

O filósofo italiano define a alma de acordo com Santo Agostinho, ou seja, uma "substância inteligente acomodada para governar o corpo" (Genovesi, 1786/1977, p. 27), cujas propriedades são o entendimento, o desejo, a liberdade, a vontade e a força. Uma das diferenças entre os autores é a definição de força, já que Genovesi a conceitua como a propriedade responsável por animar e mover o corpo e por pressentir a dor e o gosto de maneira semelhante aos animais. Para Santos, entretanto, a força é característica da alma em sua totalidade e responsável pela sua atividade, por isso não pode ser considerada como uma faculdade em particular.

As noções de força e de atividade sempre estiveram presentes nas reflexões filosóficas sobre a alma. Perrard (1834), ao tratar do conceito de Laromiguière sobre a atividade da alma, situa Tales de Mileto como um dos filósofos cuja definição de alma deriva da idéia de que ela é um princípio que se move a si mesmo. De fato, a discussão sobre a passividade e a atividade da alma diante dos objetos do conhecimento e diante das paixões é um tema sempre presente nas teorias filosóficas de diversos períodos históricos. Quanto às origens das idéias, Genovesi parte do pressuposto de que as idéias nascem em parte dos sentidos e em parte da meditação. As primeiras idéias partem dos sentidos, mas depois a alma pode meditar sobre elas, transformando-as em outras. Estaria aí a sua posição de empirismo mitigado, cuja teoria situa a origem das idéias nos sentidos, sem deixar de considerar o importante valor da racionalidade na formação delas. Para Santos, entretanto, a origem das idéias relaciona-se principalmente ao exercício da consciência, quando o espírito se volta para o eu, para o mundo físico e para a consideração de realidades como o tempo, o espaço, o justo, entre outras. Aponta assim para o problema das idéias que não podem ter sua origem na própria atividade da alma ou no mundo físico, como as noções de infinito, necessário e absoluto. Nesse sentido, o autor mineiro não adere ao empirismo mitigado de Genovesi e, 
como argumenta Rodrigues (1986), tenta superá-lo, situando a origem das idéias na consciência e trazendo à tona a discussão sobre as idéias inatas.

Além de seu diálogo com Genovesi, Santos não faz citações diretas em sua obra e assim suas matrizes teóricas não estão explicitamente colocadas. De acordo com Rodrigues (1986), Santos inicia uma intuição filosófica que ruma para o espiritualismo eclético, sem fazer uma total adesão a essa tradição já difundida na França e no Brasil. Nesse sentido, um dos importantes aspectos da obra de Santos seria a presença de temas próprios do espiritualismo, como a afirmação de um eu unitário percebido por meio da consciência.

De fato, de acordo com o levantamento realizado por Massimi (1989), diversos programas de ensino e exames de Colégios e Faculdades do século XIX, cuja orientação inspirava-se no espiritualismo eclético, possui aspectos semelhantes à proposta de Santos em sua obra. Como exemplo, anos depois da publicação do Esqueleto das faculdades de João Antônio dos Santos, em 1851, podemos encontrar o programa de exames, redigido por José de Santa Maria Amaral, para o curso de filosofia do Colégio Pedro II, definindo o eu como unidade elementar da vida psíquica, dotado das faculdades entendimento, sensibilidade e vontade (Massimi, 1990).

Mas a maioria das obras e programas de psicologia da época, mesmo de vertentes filosóficas tomistas ou empiristas, colocam a consciência, a alma, o espírito, o problema da unidade e identidade do eu e o tema da comunicação entre corpo e alma como objetos dos saberes psicológicos. Assim, a adoção do conceito de eu não é uma prerrogativa do espiritualismo eclético, já que pela definição da psicologia como ciência do espírito, realizada desde o século XVIII, dá-se gradualmente a substituição do conceito de alma pelo de eu ou de espírito. Do mesmo modo, é comum na época a definição da psicologia como estudo das faculdades da alma e sua divisão em entendimento, sensibilidade e vontade (Massimi, 1989).

Assim, João Antônio dos Santos parece se utilizar de mais de uma tradição filosófica em sua obra, não sendo possível, portanto, classificá-lo como pertencendo a um ou outro discurso, mas compreendê-lo exatamente como ele se apresenta em sua introdução ao livro: um conhecedor de diversas doutrinas sobre as faculdades da alma que realiza uma síntese sobre o tema e reconhece, nesse esforço, algo que lhe pertence.

Como Santos, Ferreira Bretas também revê as teorias sobre as faculdades da alma de sua época, mas faz sua crítica por meio da adesão aos princípios da ideologia de Laromiguière e de Perrard. O termo ideologia, marca dos ideólogos, foi utilizado pela primeira vez por Destutt de Tracy (1754-1836) para indicar a análise e descrição de funções psíquicas como as sensações e as idéias. Este filósofo, ao propor a ideologia, pensava em corrigir os defeitos do sensualismo, aprofundando a análise cognoscitiva e relacionando o tema do conhecimento com o da fisiologia cerebral (Reale \& Antiseri, 1991).

Pierre Laromiguière e Jean-Ferreol Perrard são considerados representantes dos ideólogos e Perrard têm como uma de suas maiores contribuições a autoria de livros escolares. Particularmente, Laromiguière é um autor que fez grande sucesso na França e se tornou conhecido no Brasil da época. Suas obras foram utilizadas na Escola Normal de São Paulo e citadas em trabalhos de alunos da Faculdade de Direito de São Paulo, ao lado de Damiron (1794-1862) e de Antônio Genovesi (Massimi, 1989).

Ferreira Bretas critica as teorias até então ensinadas no panorama mineiro e afirma a superioridade do sistema psicológico de Laromiguière. De fato, o autor mineiro assim como Perrard, em sua Lógica, descrevem a ideologia como uma teoria sobre as faculdades da alma capaz de superar todas as até então existentes: um novo caminho jamais traçado em filosofia, distante das teorias de Platão, Aristóteles, Descartes, Malebranche, Locke e Condillac. De maneira metafórica, Ferreira Bretas diz que a ideologia havia tomado a sciencia psychologica pela base (Ferreira Bretas, 1854 , p. 20) não como se reforma um edifício nas bases já existentes, mas construindo de novo as ciências sobre a alma ao determinar a origem das idéias nos sentimentos e a causa delas nas faculdades.

Para o autor mineiro, a ideologia trazia à luz o fato de que toda ciência nasce de um princípio que deve ser conhecido pela ação da atenção e do raciocínio humanos. Daí que a atenção fosse uma faculdade da alma tão importante e que a psicologia fosse entendida, já desde o século XVIII, como a mais útil das ciências (Vidal, 2006). Seria como a base de toda ciência. Seu ensino era tido como relevante para muitas disciplinas como o Direito, a Medicina e particularmente para a Pedagogia, entendida como direção $e$ educação das faculdades da alma (Massimi, 1989).

Tema recorrente e importante do século XIX, a preocupação com o método é bastante evidente nos escritos dos ideólogos. Assim, segundo Ferreira Bretas, o método para o conhecimento da dinâmica da alma e a sistematização da psicologia é a observação de nós mesmos feita pela experiência cotidiana.

A observação e o relato da própria consciência são, em geral, o método adotado por excelência pela psicologia desse período (Massimi, 1989). A justificativa para tal adoção era a objetividade, assegurada pela evidência da consciência que possuía a capacidade de visar naturalmente a totalidade dos fenômenos interiores. Esta perspectiva aparece claramente nas duas obras aqui investigadas, quando discutem as relações entre consciência, memória e identidade e a capacidade de a alma observar-se a si mesma em ação.

\section{Conclusão}

A obra de Ferreira Bretas pode ser entendida como diálogo e debate, dirigidos ao Esqueleto das faculdades $e$ origem das idéias do espírito humano de João Antônio dos Santos. Diálogo porque, como afirma Rodrigues (1986), Ferreira Bretas tenta continuar a reflexão iniciada por Santos sobre a unidade do eu e sua evidência por meio da consciência, além de ser comum entre os dois educadores o interesse pela psicologia. Por outro lado, existe também um debate, já que o Novo esqueleto trata das faculdades da 
Assis, R. M. (2009). Psicologia Filosófica no Século XIX: Faculdades da Alma e Relações entre Inteligência, Sensibilidade e Vontade.

alma, situando sua origem nas sensações e reduzindo-as em seus elementos, o que facilmente poderia ser interpretada como materialismo, fazendo críticas a termos, como razão, utilizados por Santos.

Ao realizar a investigação destas duas obras, é possível perceber um universo de apropriações que vão constituindo representações diversas no interior dos textos, pois nas duas obras se encontram inscritos citações e fragmentos dos mais diferentes autores e teorias. Todavia, Ferreira Bretas, ao tratar dos princípios de Laromiguière, o faz sempre citando Jean-Ferreól Perrrard, autor de Logique classique (1834). A obra de Perrard, o autor verdadeiramente citado por Bretas, faz uma sistematização das Leçons de Philosophie de Laromiguière, trazendo em suas páginas inúmeras citações literais de autoria do famoso ideólogo francês. Desse modo, é muito interessante o processo de apropriação que existe no livro de Rodrigo José de Ferreira Bretas, pois, embora se intitule como uma sistematização da psicologia de Laromiguiére, nada indica que ele tenha utilizado diretamente a obra do ideólogo francês, já que as citações do Novo Esqueleto são sempre feitas a partir da descrição de Perrard sobre a teoria de Laromiguiére. Fica evidente nesse caso, a maneira como os autores do século XIX tratavam de questões como autoria e textos extraídos de outras obras. Nesse sentido, Maria Lúcia Pallares-Burke (1996) usa o termo "tradução cultural" para apontar apropriações de obras estrangeiras realizadas por autores brasileiros, fazendo notar que essa apropriação era um fenômeno comum no século XIX brasileiro. Também Massimi (1989) aponta a apropriação que autores brasileiros fizeram de obras estrangeiras, cujos temas eram a filosofia e a psicologia como um dos objetos importantes de estudo para a história da psicologia no Brasil.

Desde o século XVIII, autores iluministas valorizaram enormemente a psicologia como sendo a mais útil de todas as ciências. Assim, nos século XVIII e XIX, a psicologia possui um papel cultural e social relevante, pois ela é considerada como a base de outras disciplinas do conhecimento, por fornecer os fundamentos necessários para a reflexão e investigação das condições inerentes ao processo de conhecimento de si e da natureza (Massimi, 1989; Vidal, 2006). As idéias sobre o espírito humano e variados conceitos descritos, elaborados por João Antônio dos Santos e Ferreira Bretas, demonstram a inserção desses autores em um projeto de modernidade que é bem próprio do século XIX. A aproximação ou adesão à ideologia e ao espiritualismo eclético como sistema que tenta estabelecer certas sínteses entre a tradição, principalmente as mais antigas, e as novas idéias sobre método, ciência, ser humano e conhecimento, é uma das características dessa inserção.

\section{Referências}

Alberti, S. (2003). Crepúsculo da alma: A psicologia no Brasil no século XIX. Rio de Janeiro, RJ: Contra Capa Livraria.

Antunes, M. A. M. (1998). A psicologia no Brasil: Leitura histórica sobre sua constituição. São Paulo, SP: Unimarco.
Campos, R. H. F. (1992). Notas para uma História das idéias psicológicas em Minas Gerais. In R. F. H. Campos (Ed.), Psicologia: Possíveis olhares, outros fazeres (pp. 13- 63). Belo Horizonte, MG: Conselho Regional de Psicologia.

Ferreira Bretas, R. J. (1854). Novo esqueleto das faculdades e origem das idéias do espírito humano segundo os princípios de Mr. Larominguiere ou da psicologia vigente. Ouro Preto, MG: Tipografia do Bom Senso.

Genovesi, A. (1977). Instituição de lógica. Rio de Janeiro, RJ: Documentário. (Original publicado em 1786)

Jacó-Vilela, A. M., Esch, C. F., Coelho, D. A. M., \& Rezende, M. S. (2004). Os estudos médicos no Brasil do século XIX: Contribuições à psicologia. Memorandum, 7, 138-150. Retrieved July 3, 2007, from http://www.fafich.ufmg.br/ $\sim$ memorandum/artigos07/jacovilela01.htm

Leite, A. F. P. (2005). A formação da cultura filosófica escolar mineira no século XIX: Uma filosofia de compêndio (1854 1890). Dissertação de Mestrado não-publicada, Faculdade de Educação, Pontifícia Universidade Católica de Minas Gerais, Belo Horizonte, MG

Massimi, M. (1989). A psicologia em instituições de ensino brasileiras do século XIX. Tese de Doutorado não-publicada, Universidade de São Paulo, SP.

Massimi, M. (1990). História da psicologia brasileira: Da época colonial até 1934. São Paulo, SP: EPU.

Nepomuceno, D. M., \& Campos, R. H. F. (2004). Fontes para difusão das idéias psicológicas em Minas Gerais entre 1830 e 1930. Memorandum, 6, 114-123. Retrieved July 3, 2007, from http: //www.fafich.ufmg.br/ memorandum/artigos06/ nepcampos01.htm

Paim, A. (1977). Introdução. In A. Genovesi, Instituição de lógica (pp. 5-11). Rio de Janeiro, RJ: Documentário.

Pallares-Burke, M. L. (1996). Nísia Floresta, o Carapuceiro e outros ensaios de tradução cultural São Paulo, SP: Hucitec.

Perrard, M. J. F. (1834). Logique classique dáprès lês príncipes de philosophie de M. Laromiguière: Vol. 1. Paris: BrunotLabbe.

Reale, G., \& Antiseri, D. (1991). História da filosofia: Do Romantismo até nossos dias. São Paulo, SP: Paulus.

Rodrigues, J. C. (1986). Idéias filosóficas e políticas em Minas Gerais no século XIX. Belo Horizonte, MG: Editora da Universidade de São Paulo.

Santos, J. A. (1847). O esqueleto das faculdades e a origem das idéias do espírito humano, obra mui útil para os moços que se applicão ao estudo de Philosophia. Mariana, MG: Tipografia Episcopal de Mariana.

Vidal, F. (2006). Lês sciences de l'âme - XVI - XVIII siècle. Paris: Honoré Champion.
Recebido: 30/11/2006

$1^{a}$ revisão: $29 / 08 / 2007$

$2^{a}$ revisão: $12 / 09 / 2008$ Aceite final: 10/10/2008 